\section{Infecciones respiratorias altas y suspensión de cirugía electiva}

\author{
Dr. Julio Yarmuch Gutiérrez \\ Editor \\ Revista Chilena de Cirugía \\ Estimado Sr. Editor:
}

La suspensión de un procedimiento quirúrgico electivo es multifactorial. Llama la atención que un número importante de cirugías electivas son suspendidas de forma inesperada el mismo día del evento quirúrgico porque el paciente presenta alguna enfermedad intercurrente de inicio agudo las horas previas al procedimiento, siendo las infecciones respiratorias altas (IRA) la causa más frecuente.

La historia reciente o actual de una IRA suele ser razón suficiente para suspender una cirugía electiva, dependiendo del criterio de cada equipo quirúrgico. Esto debido al riesgo aumentado de complicaciones de vía aérea alta y broncopulmonares que se podrían generar en el período perioperatorio, como una mayor incidencia de laringoespasmo y broncoespasmo por una vía aérea hiperreactiva, y atelectasias y neumonías por acumulación de secreciones bronquiales e hipoventilación.

Pensamos que deberían ser utilizados criterios más objetivos, basados en la mejor evidencia médica actualmente disponible, para decidir la realización o suspensión del procedimiento quirúrgico electivo en este contexto y no dejar la decisión a la discreción de cada equipo quirúrgico. Creemos que se debe realizar una acuciosa evaluación preoperatoria en aquellos pacientes que serán sometidos a cirugía electiva y que tienen una IRA concomitante, evaluando los riesgos y beneficios del procedimiento quirúrgico, $\mathrm{y}$ no suspender sin una causa debidamente justificada. Lo anterior no es aplicable en cirugías de urgencia o emergencia y en pacientes con un estado basal deteriorado y riesgo vital, donde la necesidad de cirugía es más importante que el riesgo de complicaciones respiratorias perioperatorias.

La tendencia habitual desde hace muchos años es suspender gran parte de los pacientes que llegan a intervenirse quirúrgicamente con síntomas y/o signos de IRA, independiente de la gravedad de éstos. La evidencia actualmente disponible sobre la necesidad absoluta de suspender la cirugía en este tipo de pacientes no es clara, por lo que sigue siendo un tópico controversial ${ }^{1,2}$. Las últimas revisiones respecto del tema presentan cada vez mayor apoyo a que la decisión debe ser tomada en conjunto por todo el equipo quirúrgico y teniendo en cuenta a cada paciente en particular ${ }^{3}$.

Uno de los problemas más importantes al decidir una suspensión es como se define IRA, que puede ir desde síntomas simples y banales, como congestión nasal, rinorrea, tos seca, odinofagia, etc, hasta síntomas más marcados, como tos con secreciones, congestión importante de la vía aérea superior y fiebre. Los estudios al respecto también presentan el mismo problema, ya que los criterios de definición de IRA tienden a ser rígidos y no se relacionan necesariamente con el riesgo de presentar complicaciones asociadas. Un estudio identifica a la percepción subjetiva de IRA por parte de los padres como el mejor predictor para la aparición de complicaciones respiratorias perioperatorias en la población pediátrica, especialmente laringoespasmo ${ }^{4}$, lo que podría ser extrapolado a la población adulta como la percepción de IRA por parte del mismo paciente.

La IRA intercurrente suele ser un problema más importante en la población pediátrica que en la adulta, ya que existe una incidencia superior de complicaciones debido a mayor producción de secreciones e hiperreactividad bronquial provocada por las infecciones virales, asociándose principalmente a laringoespasmo, broncoespasmo e hipoxemia ${ }^{5}$. Estas complicaciones se presentan con mayor frecuencia en niños con antecedentes de enfermedades crónicas que aumenten la reactividad de la vía aérea, padres fumadores, cirugía de la vía aérea alta, presencia de secreciones abundantes y utilización de intubación endotraqueal durante la cirugía ${ }^{6}$.

En los pacientes con IRA sometidos a cirugía no se ha demostrado una significativa mayor morbilidad residual ni rehospitalización relacionadas a estos eventos respiratorios perioperatorios ${ }^{7}$. La gran mayoría de los pacientes que han requerido rehospitalización tienen una recuperación sin complicaciones. Se han descrito muy pocos casos de muertes en estos pacientes, siendo imposible descartar otros factores que también podrían haber contribuido a la mortalidad $^{8}$. En los pacientes adultos existe mucha menos evidencia que avale o no la suspensión de una cirugía electiva y las complicaciones relacionadas a una IRA.

De acuerdo a la evidencia médica disponible y a nuestra experiencia, los pacientes con una IRA con síntomas leves pueden ser sometidos a una cirugía electiva, siempre y cuando no presenten comorbilidades cardiovasculares $\mathrm{y} / \mathrm{o}$ respiratorias.

Por otro lado, creemos recomendable suspender una cirugía cuando el paciente presente una IRA severa, asociada a fiebre, mialgias, disnea y/o signos 
pulmonares como sibilancias, roncus, espiración prolongada y estertores gruesos. Así mismo, si el paciente tuvo una IRA severa durante las últimas 4 semanas previas a la cirugía 9 . Esto último no es una recomendación absoluta y se debe evaluar paciente a paciente, sobretodo en niños, ya que por la gran frecuencia de IRA que presenta la población pediátrica se hace difícil que permanezcan asintomáticos durante este período de tiempo.

Si una cirugía electiva es suspendida por una IRA intercurrente, existe consenso relativo de reprogramarla al menos 4 semanas posteriores a la finalización del cuadro infeccioso, ya que el mayor riesgo de complicaciones respiratorias se presenta durante este período de tiempo, probablemente secundario a la hiperreactividad de la vía aérea ${ }^{6}$.

De lo expuesto, deberíamos realizar una evaluación preoperatoria completa a los pacientes, definiendo cuáles tienen un riesgo real de presentar complicaciones respiratorias, para así evitar la cancelación de cirugías de forma innecesaria.

Saludan atentamente a usted,

Int. Maximiliano Zamora H., Drs. Claudio Nazar J., Ricardo Fuentes H., Guillermo Lema F. División de Anestesiología. Escuela de Medicina, Facultad de Medicina. Pontificia Universidad Católica de Chile. Santiago, Chile.

\section{Referencias}

1. Jacoby DB, Hirshman CA. General anesthesia in patients with viral respiratory infections: an unsound sleep? Anesthesiology. [Comment Editorial]. 1991 Jun;74:969-72.

2. Cohen MM, Cameron CB. Should you cancel the operation when a child has an upper respiratory tract infection? Anesth Analg. [Research Support, Non-U.S. Gov't]. 1991;72:282-8.

3. Cote CJ. The upper respiratory tract infection (URI) dilemma: fear of a complication or litigation? Anesthesiology. [Comment Editorial]. 2001;95:283-5.

4. Schreiner MS, O'Hara I, Markakis DA, Politis GD. Do children who experience laryngospasm have an increased risk of upper respiratory tract infection? Anesthesiology 1996;85:475-80.

5. Serafini G, Cavalloro F, Mori A, Rossi C, Tagliaferri C. Upper respiratory tract infections and pediatric anesthesia. Minerva Anestesiol. [Review]. 2003;69:457-9.

6. Tait AR, Malviya S, Voepel-Lewis T, Munro HM, Seiwert M, Pandit UA. Risk factors for perioperative adverse respiratory events in children with upper respiratory tract infections. Anesthesiology. [Clinical Trial Research Support, U.S. Gov't, P.H.S.]. 2001;95:299306.

7. Rolf N, Cote CJ. Frequency and severity of desaturation events during general anesthesia in children with and without upper respiratory infections. Journal of clinical anesthesia [Comparative Study Research Support, NonU.S. Gov’t]. 1992;4:200-3.

8. Konarzewski WH, Ravindran N, Findlow D, Timmis PK. Anaesthetic death of a child with a cold. Anaesthesia. [Case Reports Letter]. 1992;47:624.

9. Tait AR, Malviya S. Anesthesia for the child with an upper respiratory tract infection: still a dilemma? Anesth Analg. [Research Support, Non-U.S. Gov't Review]. 2005;100:59-65. 